\title{
Ornamented Worlds and Textures of Feeling: The Power of Abundance
}

\section{Summary}

Human development takes place in an ornamented redundantly patterned and highly repetitive - world. The emergence of knowledge takes the form of episodic unpredictable synthetic events at the intersection of the fields of internal and external cultural meaning systems - through the mutually linked processes of constructive internalization and externalization. Patterns of decorations - ornaments - are relevant as redundant "inputs" into the internalization/externalization processes. Ornaments can be viewed not merely as "aesthetic accessories" to human activity contexts but as holistic devices of cultural guidance of human conduct that acts through the subjectivity of personal feelings. This guidance is peripheral in its nature - surrounding the ordinary life activities with affectively oriented textures of cultural meanings.

How do we make sense of our environments? In this paper I suggest a holistic view of human development on the basis of coordination of patterns - of the person's environments, and of one's interior spaces of affective thinking. The theoretical goal here is to take my theory of internalization/externalization (Lawrence \& Valsiner, 1993, 2003; Valsiner, 1997, 2007b) and the hyper-generalization theory of affect (Valsiner, 2005, 2007a) to the field of our everyday life contexts. These contexts are saturated with highly repetitive patterns of visual and auditory kinds. They are patterns we encounter in our activities. All encounters of organisms with environments can be viewed as processes of coordinating patterns - camouflage of body patterns relating to patterns of biological environments, mating based on body display patterns, textures of surfaces for walking, sucking, swimming, or crawling. Life is patterned - rather than dependent on singular "stimulus"-"response" relationships. Of course that is understood in psychology since 1890s (Ehrenfels, 1890/1988), but its implications for our general knowledge have not been elaborated.

In the case of human development, such double patterning of life - environmental and intra-mental - acquires a future-oriented flavor. Patterns are constructed for a purpose - guiding the person encountering those towards some goal orientation. Most of these constructed cultural patterns are peripheral in their relating with our personal worlds - we live among them rarely noticing them in the background. We even consider them "mere decorations" or ornaments. Our lives are ornamented lives and that nature of our activity contexts sets up new demands for psychology's methodology (Diriwächter and Valsiner, 2008). Instead of continuing the practice of breaking complex 
wholes into analytic elementary constituents, our methodology leads us to field-theoretic method construction.

\section{What are ornaments - and what do they do?}

We surround ourselves with a myriad of seemingly useless things. Human beings create decorations - patterns - largely following patterning examples from nature that for us look beautiful - while they for the species who use these patterns are of utilitarian value. The colorful feather patterns of birds look beautiful to the human eye, while their functional value for the birds themselves may be in mating regulation or in merging with the environment to confuse predators. Birdsongs can be models for human music - but music is a pattern created by humans with communicative functions.

Cultural constructions differ from nature's patterns. While human-made ornaments may mimic nature, they abstract from natural patterns and guide human meaning-making. The whole enterprise of cultural organization of human lives entails the construction of ways of distancing oneself from the here-and-now settings while remaining within the settings (Valsiner \& Rosa, 2007). Ornaments lead such abstracting generalization efforts - they are repetitive patterns of some abstracted aspects of reality - rather than close to original "copies" of the reality. They trigger further psychological generalization:

...consists in the subsequent naturalization of a pure ornament, i.e., an abstract form, and not in the subsequent stylization of the natural object. The crucial factor is contained in this antithesis. For it reveals that the primary element is not the natural model, but the law abstracted from it. It was therefore the artistic projection of the regularity of organic structure which, in consequence of the intimate organic connection of all living things, afforded the basis for the aesthetic experience of

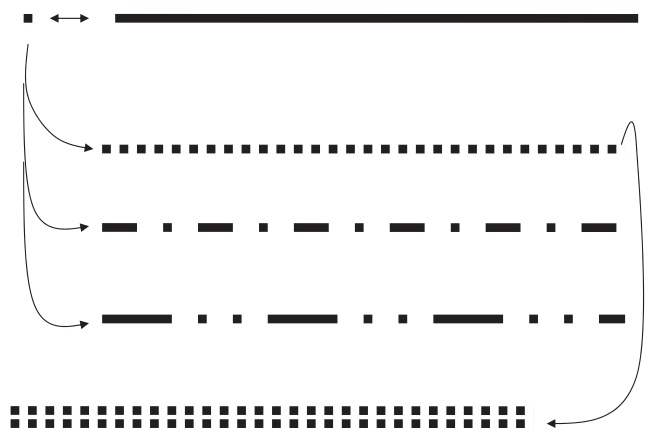

Figure 1. The birth of the minimal ornament

the spectator, and not concordance with the natural model. (Wörringer, 1963, p. 60)

Our contemporary - mostly empirically oriented - anthropology and psychology that emphasizes human immersion in "situated activity contexts" has overlooked the centrality of the agency - of the person who, while being involved within a context, moves far beyond it in one's psychological construction of one's "inner infinity" (to use William Stern's term here). The affective synthesis - generalization emphasized by Wörringer - is the center of human aesthetic experience (Vygotsky, 1971). Yet we need to know how such aesthetic experience is afforded, and how it functions in situated activity settings.

Where do ornaments begin? Elementary graphic forms - points or their extensions lines - by themselves do not amount to being

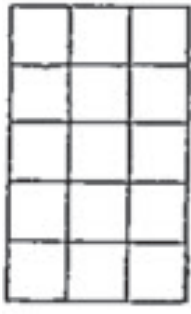

A

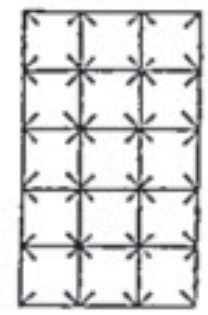

B

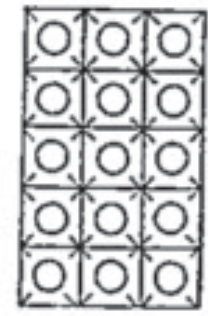

C
Figure 2. Creating the field - ornament emerging from combination of features (Jones, 1856, p.190) 
an ornament (Figure 1). It takes some form of repetition of the pattern to create an ornament. Such repetition of patterns can be woven together with that of other patterns and located in selected locations of human ordinary life (and death) environments. Thus, in his description of the basics of Moorish ornament, Jones (1856/2001, p. 190) explained the principle of combination (Figure 2)

In surface decorations, any arrangement of forms, as at A, consisting only of straight lines, is monotonous, and affords but imperfect pleasure; but introduce lines which tend to carry the eye towards the angles, as at B, and you have at once an increased pleasure. Then add lines giving a circular tendency, as at $\mathrm{C}$, and you have now complete harmony. In this case the square is the leading form or tonic; the angular and the curved are subordinate.

Ornaments are patterns with order - a grammar of forms (Salingaros, 1996).

Yet the meaning of ornament - decoration is often linked with the notion of a non-functional or excessive kind of decoration. They are there - yet we may confess that their only function is aesthetic. But why are we so sure of

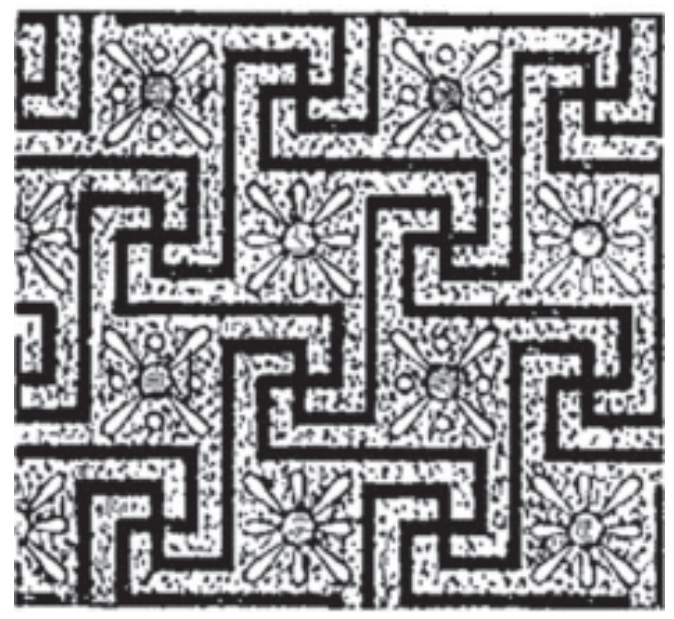

A that? Ornaments have been systematically created by human beings long before the meaning of beauty for its own - aesthetic - sake. There must exist some social reasons for creating decorated patterns for the ceilings of the homes of the dead (Figure 3) as well as those of the living (Figure 4)

Ceilings as places for ornamentation are interesting. It is obvious that most human everyday activity takes place within the vertical plane - hence ornamentation located on our vertical surfaces is of primary function for our psychological environments. Thus, walls, screens, windows, etc. are often decorated by ornaments. Yet the history of recorded ornaments from Ancient Egypt to our days includes ceiling ornaments - leaving us with the functional question of why would the horizontal structures - floors, ceilings - be ornamented. Such horizontal decoration can be parallel to the build-up of relevant buildings - churches, temples, or political monuments - upwards. When the mundane everyday activities encounter vertically layered environmental settings, their transcendental counterparts are organized into horizontally located layers facing either upwards (ceilings, church towers, etc) or downwards (floors, catacombs).

The habits of sleeping and waking bring the patterning of the ceilings to the field of at-

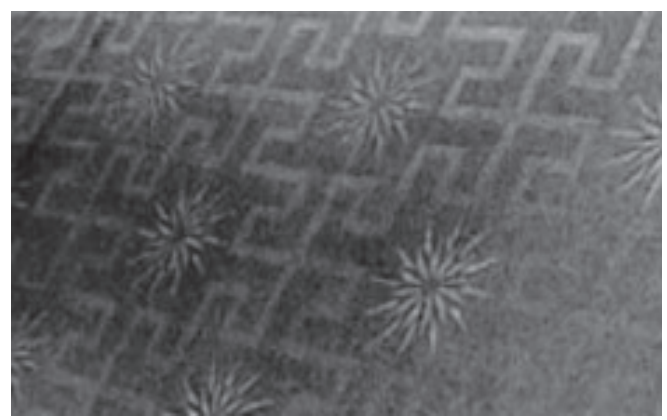

B

Figure 3. Ceiling ornament in an Ancient Egyptian tomb (A) and in a $20^{\text {th }}$ century public building $(B)$ 
tention of architects and designers. Worries of parents who decorate the child's sleeping environments with different patterns are functionally examples of ceiling decorations - the need to consider what kind of visual patterns appear in front of the child's eyes when s/he wakes up, is itself a tacit recognition of the function of ornaments in human development.

\section{Ornaments as cultural arenas of meaning construction}

Ornaments are omnipresent. We can find ornaments below us (on the surfaces on which we move), on all sides (in between which we move) and above our heads - in the form of the natural clouds and cultural decorations of ceilings. Such holistic patterning of our perceptual environment is obvious in everything that surrounds us - architecture, textiles, wallpaper, monuments, etc. They are also right on our bodies - in the form of tattoos and body painting, near our bodies in private (underwear) and public (costumes), and they envelope our immediate activity contexts of sleeping (lace decorations on pillows and bedspreads), eating (patterned tablecloths and napkins). Furniture is often filled with ornaments - at home and in public settings. Walls are covered by wallpaper - ornamented - or made of ceramic tiles.

\section{Tension within the exaggerated opposition PLAIN $<$ FANCY}

The history of ornaments is usually elaborated in terms of a history of art and architecture (Hamlin, 1923). When cultural objects were constructed, the surfaces may remain as those functionally were (plain) - or become covered with add-ons the function of which is decorative. The contrast to the decorated (A) state is its non-decorated ("PLAIN") opposite (nonA) - in line with the A-non-A perspective on meaning (Josephs, Valsiner, \& Surgan, 1999). Here the dynamics of A-non-A acquires a new
Non-A

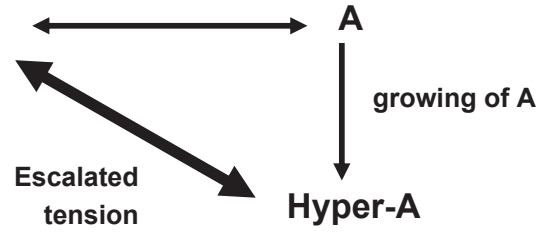

Figure 4. The growth of a sign and escalation of affective tension

focus - a growth from A (decorated) to HyperA (hyper-decorated - "FANCY" - Figure 4)

The latter can take the form of exaggeration of selected parts of the figure, or through proliferation of the redundancy - by repetition of the pattern of its ground that is ornamented. By manifold replicating, a simple element of an ornament covers the sensory field of the person in full, thus "keeping the person within the field."

Differences in the trajectories of resolving the tension between PLAIN (non-A) $<>$ FANCY (hyper-A) in the construction of the exteriors of the building between different European societies - Spain, Italy, the Netherlands - demonstrate the prevailing need to strategically regulate the activity fields of everyday public worlds. The "war against decorations" in churches around the Protestant Reformation in Europe is an example of how the meaning of excess in decorations was made into an ideological and political issue that led to destructive consequences like vandalism in churches. The "exaggerations" of these decorations became viewed as breaches of visual piety - the $\{$ non-A $\}<>$ hyper-A $\}$ opposition moved in the direction of a positive valuation of the non-A pole. The need to destroy Catholic symbolic figures first - before turning to the human beings who revered these figures was the first step. Likewise, pulling down the monument of a deposed dictator after the first entrance into a city - the full conquering of which may take years - indicates the rhetoric power of hyper-exaggerated symbols.

The tension can lead also to an opposite 


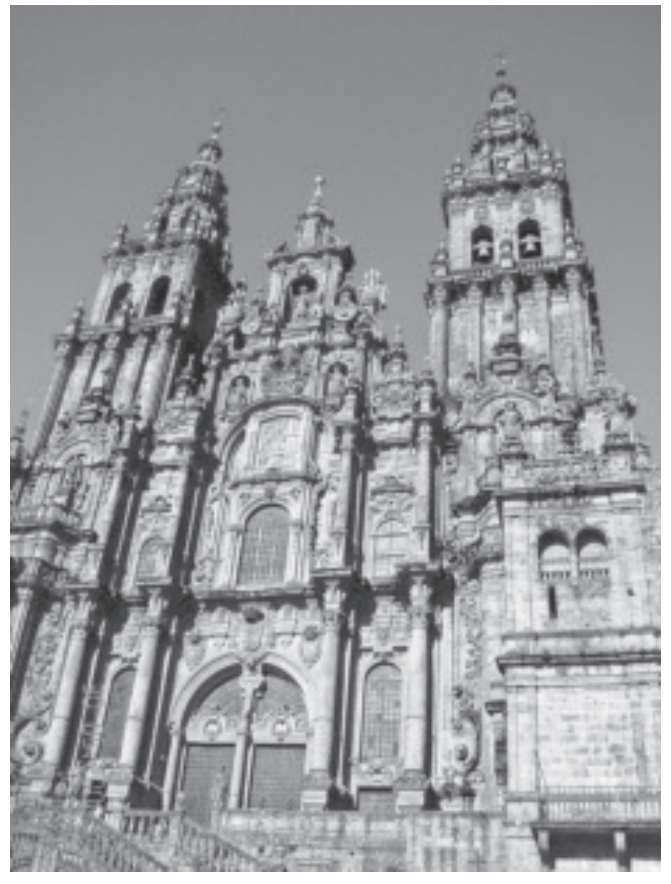

Figure 5. A "frantic" cathedral-Santiago de Compostela

build-up of symbols - on the hyper-exaggerated side. From the history of architecture we know of the emergence of the architectural style of churriguresco in $18^{\text {th }}$ century Spain (Hamlin, 1923, p. 291-293) that signifies hyper-decoration of selected parts of the architectural space - described as frantically Baroque (see Figure 5). Church architecture in the Spanish colonial domains in the Americas is filled with such abundance of decoration. From the very emergence, these hyper-decorated objects were noticed as such - yet their function of exaggeration remained in place and regulated the social lives of people who may have found such ornaments worth talking about.

Exaggeration guarantees redundancy - and redundancy is the only way to guide the direction of open systems - which (by definition) are unpredictable. As Edmund Leach pointed out - "the jumble is the message" (Leach, 2000, p. 126) - yet which message, for whom, and how does it work? Ornamentation in its abundance - or its purposeful absence in the puritan worlds (i.e. "abundance of nothing") is an example of how human living takes place in a field of exaggerations that the person cannot leave (Valsiner, 2006, 2007a).

The imposing appearance of cathedrals to pilgrims arriving on their long walk would turn the excessive details of the architectural ornaments into images that link the mundane with the supernatural. The overwhelming impression of the grandiose pattern of abundantly decorated building feeds into the meaning making facing the scene. Yet ornaments on buildings can be found anywhere (Figure 6). By proliferation of their pattern in space and time ornaments create an inescapable field structure. Anybody who is passing by the house depicted in Figure 6 - without any goal of carefully examining the pattern - necessarily is exposed to the pattern through at least peripheral vision.

In the acoustic domain, the music playing in the background of an activity setting - shopping, wedding, etc. - constitutes an all-encompassing auditory ornament for the activity. In child development that is exemplified by the Suzuki method in music education that begins from enveloping the child completely in the musical environment. Furthermore - the di-

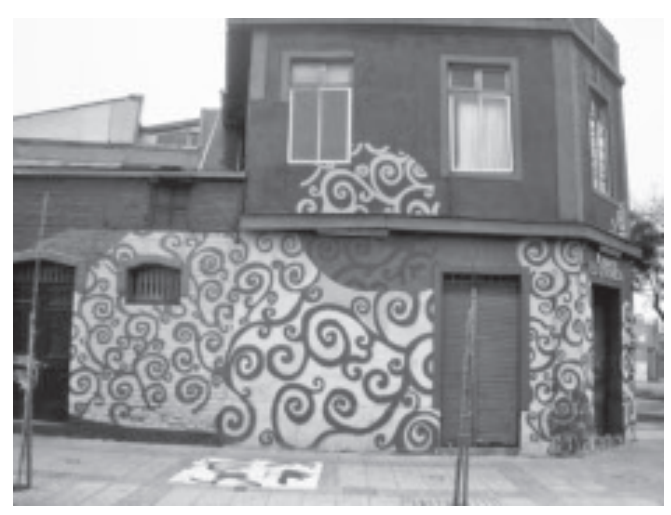

Figure 6. Side ornament of a house-Santiago de Chile 
rect link of the auditory and visual-kinesthetic ornamentation of situated activity context is the tradition of singing while performing an activity (see Goodale, 1995). In the context of singing-while-doing, the actor establishes the unity of the internal affective sphere with the external socially canalized activity frames. For example, the song to be sung while collecting honey among hunters-gatherers of the Nilgiri Hills (Demmer, 1997) catalyzes the personal meaningfulness of the activity. Not surprisingly, many social rituals - religious, political, or life cycle transition linked - involve scripted mandatory singing. The move from background (external) ornaments to ornaments that catalyze the internalization of the meaning system through fusing the action and its ornament (e.g., acting while singing) unites the ornamented and theatrical action worlds.

Most of human living is theatrical - persons assume social roles and transform these (Turner, 1974). In that context human role-assuming involves selective and purposeful exaggerations - dramatizations - that create affective meaning tensions which lead to ruptures (Zittoun, 2006) and syntheses of new meanings.
Through the unity of analogy and opposition (Foster, 1979) - by way of escalated oppositions - we can see the emergence of novelty. It is as if the developing human being - in the act of experimenting with the meanings system and driving the existing opposition to the breaking threshold - guides one's own development. Such rupture is a goals-oriented moment of chaos - often seen as affective turmoil - that becomes reconstituted into a new oppositional ( $\mathrm{B}<>$ non-B) state that grows out of the $(\mathrm{A}<>$ non- $\mathrm{A})$ contrast.

\section{Temporal structure of} ornamented activity settings

The use of ornaments in situated activity contexts gives us a picture of ground/figure relations in the motion of the given activity. Most human activities entail a movement of the actor through some environmental structures - entrances from open to closed spaces (living room to bedroom, street to house; square to church or temple, etc.). The routes of such entries are often strategically decorated by ornaments - as the entrances to most churches exemplify. External ornaments in our

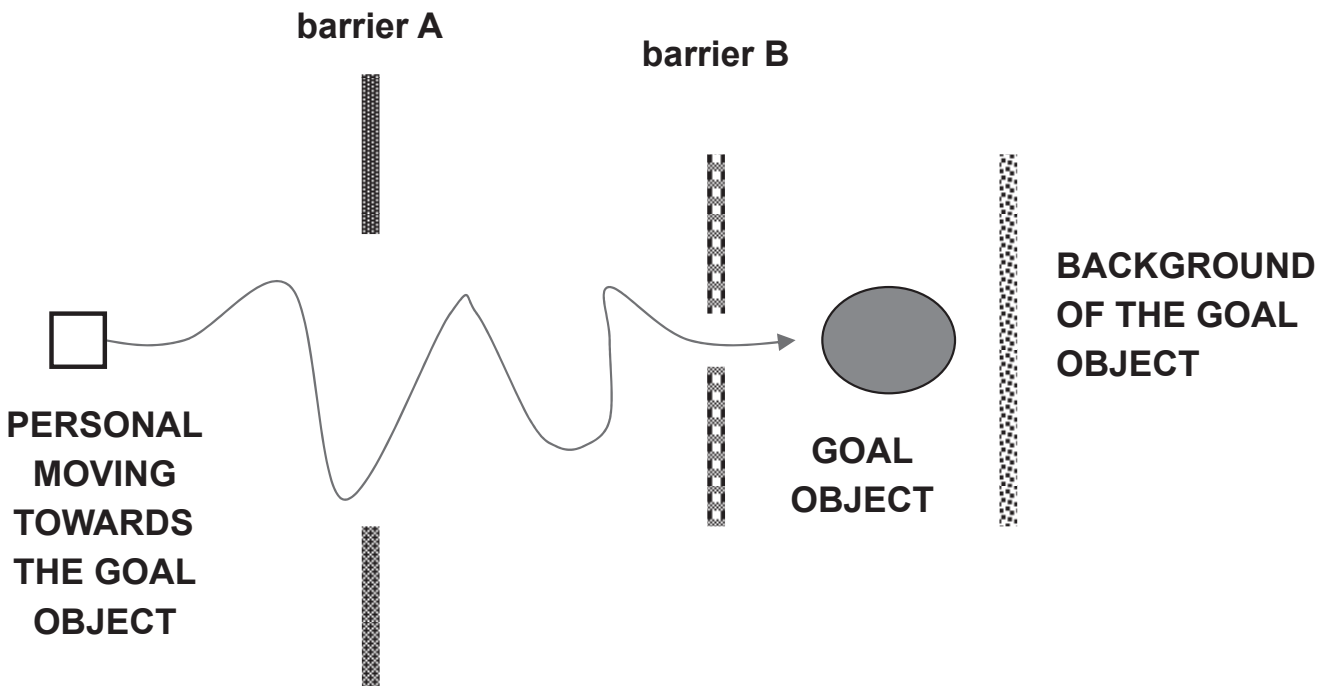

Figure 7. Strategic locations of ornaments in a situated activity setting (a generic example) 
life contexts are strategically situated to guide us towards the goal objects set up for us by goal-directed social institutions (Figure 7).

Human activities are organized through movement - the goals-oriented agent moves through some environmental settings to reach the goal. In that movement, all the patterning of the setting is exposed as peripheral input to the sensory system of the actor. The access to the goal region (Figure 7) may be guided by various barriers that limit the actor's movement towards the goal (A and B in Figure 7). It is precisely the ornamentation of these barriers that functions as a peripheral cultural canalization device targeting the acting person who is moving towards the goal.

Human activities are bounded by constraint structures (Valsiner, 1997) - and entail entrances (as well as exits) from these situated contexts. The tendencies to use ornaments for entrances - framing the surroundings of doors, or doors themselves - are present in architectural spaces in human history. The ornamentation of the entrance can be contrasted with its absence further away from the boundary of the everyday activity that it marks (Figure 8).

Last - but not least - the goal object itself may be surrounded by an ornamented ground that

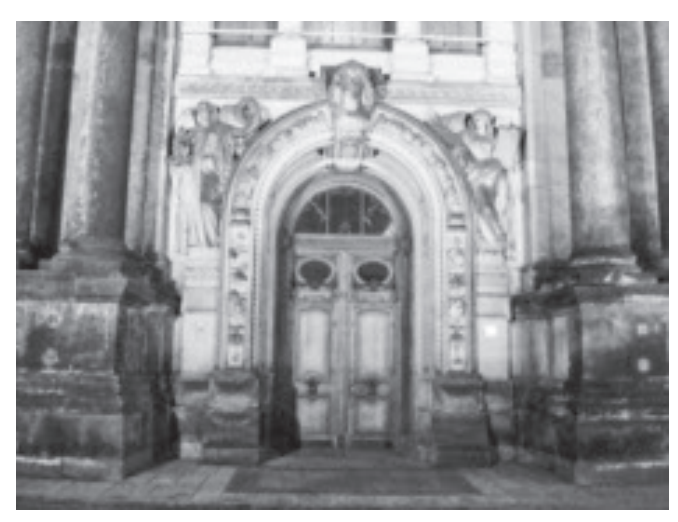

Figure 8. An entrance to a building in Dresden frames it. The example of such ornamented guidance of affect is the mediaeval focus on Schaufrömmigkeit (piety of seeing - Morgan, 1998, p. 59) - presentation of scenic images of the deity in contexts that, while giving primary focus to the image, surround the viewer with an affective tone that guides him or her towards feeling into the event depicted. Through the processes of empathy and sympathy the meanings of the main visual (or acoustic) narrative become internalized/externalized. They lead the formation of an internal value system - of the subjective ornament of meanings. Values are internal subjective meaning fields that totally capture and guide the person who has constructed them. They can be labeled but the labels never capture the holistic nature of their function.

\section{Internalizing ornaments}

My main point here is the parallel to external ornaments within the developing mind - in the form of the establishment of hyper-generalized affective fields (Valsiner, 2005 - and Figure 9 below). These fields are semiotic - presenting the affective meaning for the meaning-maker.

The actions of persons and social institutions converge on the set-up and maintenance of such holistic promoter signs. Creating ornaments guarantees that the experience of these decorations is surrounded by such signs hence keeping the person within the field surrounded by general direction for ways of feeling within the given environment. The affective domains of human existence are the primary domains for guiding human thinking - affective input is the basis for effective rationality.

\section{A hierarchy of affective semiotic fields}

The hierarchy of levels of semiotic mediation of affective processes is depicted in Figure 9. Level 0 is the universal - for all of the animal kingdom - physiological anticipation about 
the immediate next future event in life. Based on that level, the organisms can develop a generalized, non-mediated "feeling tone" (or anticipatory affective state, a kind of undifferentiated awareness of something - positive, negative, or ambivalent - that is about to happen). These Level 1 phenomena do not require semiotic mediation - they are generalizations based on imagery and activity. It is at this level where biological regulatory patterns - those of body patterning and coloring (Badyayev \& Langdeen, 2007) that behavioral interactive events such as mating are organized. Semiotically mediated (i.e., cultural) organization of the affective field has its roots at the move from Level 0 to Level 1. The examples of meanings that exist in the animal worlds - described by Jakob von Uexküll in his Bedeutungslehre (1940/1982) - are of Level 1. The person's primary affective field is already oriented by the person's previous experience.

The quasi-differentiated affective complex of the affect-within-activity conglomerate becomes articulated at Level 2 - where a specific naming of emotions present "in" the experiencing person, by the person oneself, is taking place. The undifferentiated field of a particular directional quality (e.g., positive, negative, or ambivalent) becomes reflected upon through assigning the present state of the field a specifying name for the emotion felt. So, the person can say "I am sad", "I am disgusted", "I am happy" or talk about emotions like HAPPINESS, SADNESS, ANGER, SURPRISE, etc. The process of feeling-in-activity has been changed into a static depiction of "states of feeling" - de facto entities ("happiness") based on states ("I am feeling something positive") which on their side were based on the feelingwhile-acting.

Generalization of the entified signs ("happiness", "sadness") proceeds in the direction of gradual loss of the categorical nature of the emotion terms and their immersion in the gen- eralized field (Level 3). The person can reference one's feeling in general direction terms ("I am feeling GOOD") - yet it is a generalized vague category ("good", "bad") rather than the emerging first generalization (move Level 1à Level 2) of "I am feeling SOMETHING positive".

The sign-mediated field of feelings can reach the highest level of hyper-generalization at Level 4. This entails the emergence of feeling fields that overtake the person's psyche in its totality. The person "just feels" something - but cannot put that feeling into words. Examples of aesthetic feelings - catharsis experienced during a theatre performance, reading deeply moving poems or prose, or in an interpersonal situation of extreme beauty, indicate that the human affective field can become undifferentiated as a result of extensive abstraction of the emotions involved, and their overgeneralization to the person's general feelings about oneself or about the world. Theoretically, that process entails internalization and abbreviation.

Values are basic human affective guidance means that are ontogenetically internalized, but their externalization can be observed in any aspect of human conduct. Yet as they have reached such a hyper-generalized way of being, they are no longer easily accessible through verbally mediated processes. We can decisively act as directed by our values - but are ill at ease telling others what these values are. If we succeed, we have performed the Level $4 \rightarrow 3$ translation of a hyper-generalized semiotic field into general verbal statements (e.g., "I feel totally dedicated to science") that may refer to the direction of the values but cannot capture them in their entirety. Values are not entities - but dynamic semiotic fields. In human life, affective fields of higher kind as depicted in Figure 9 - regulate experience in its totality. Affective fields can be hyper-generalized meanings that have left their original context of emergence and flavour new experi- 


\section{Level 4}

(hyper-generalized affective semiotic

field-creates

subjective Gefühston)

\section{Level 3}

(generalized categories of feeling)

\section{Level 2}

(specific emotion terms)

\section{Level 1}

(general immediate pre-semiotic feeling subjective experience and its "natural" Gefühston)

\section{Level 0}

PHYSIOLOGICAL

LEVEL

(excitation and inhibition)

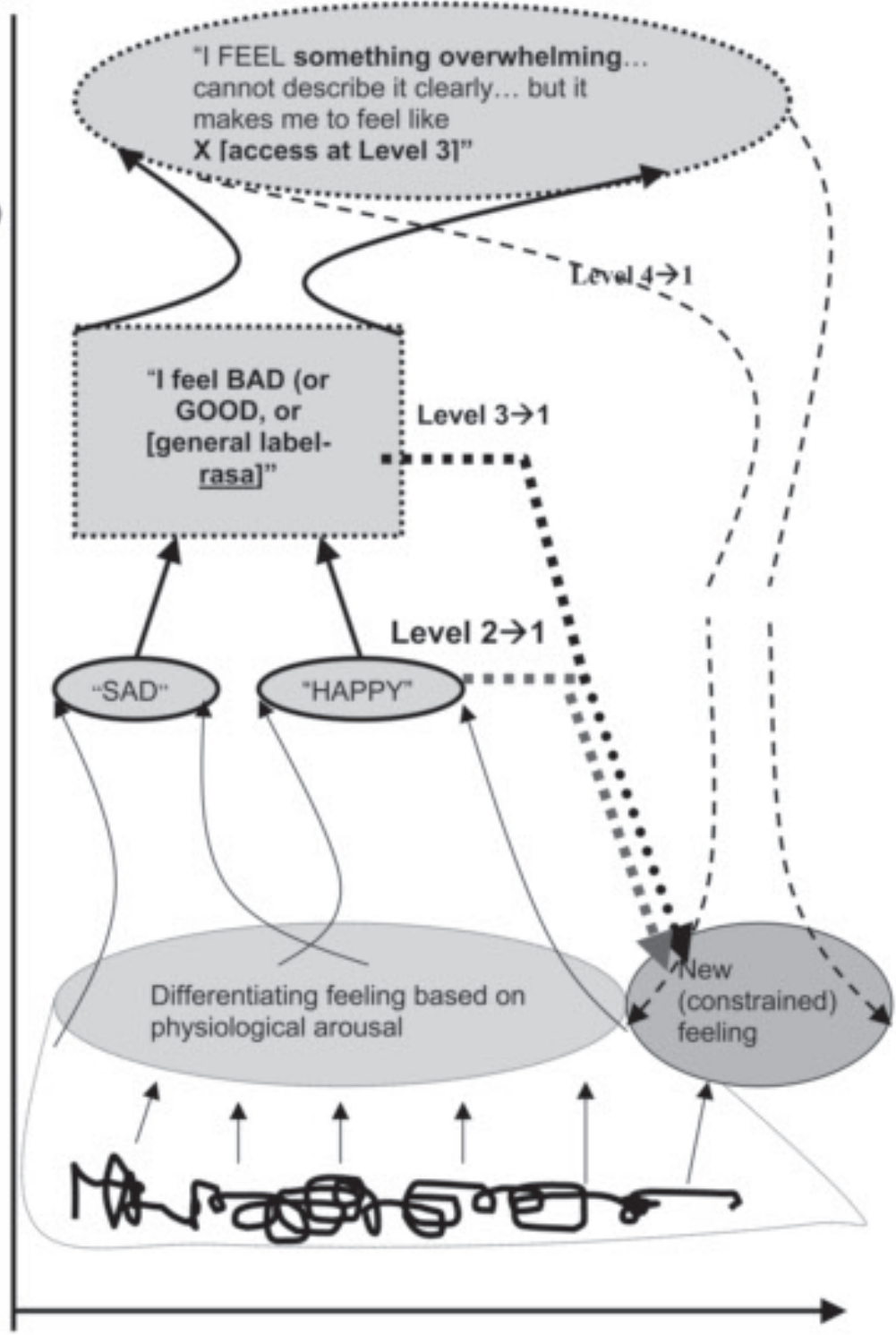

Figure 9. Levels of affective fields (from Valsiner, 2007, p. 312)

ences. Thus, a person may develop the notion "life is unfair" from a series of life events of being mistreated.

\section{How development happens - or: On the importance of wallpaper}

Ontogeny involves weaving together the patterned flow of encounters with the textured world, and the internal subjective affective fields that are constantly under construction through hyper-generalization. As is usual, we can begin to understand the extraordinary nature of very ordinary life events when there are ruptures in the ordinary.

In around 1861 in a small country home of a former officer of the Russian army, far from 
St. Peterburg, repairs were being made to refurbish the house. It turned out there was not enough wallpaper brought from the capital and the decision was made to use left-over paper to cover the children's bedroom walls. By coincidence, lithographic lecture notes of the father on mathematics - found on the attic - were used. The retrospective account by a 11-year old girl captures the flavor of the new life this makeshift wallpaper created:

As I looked at the nursery walls one day, I noticed that certain things were shown on them which I had already heard mentioned by Uncle. Since I was in any case quite electrified by the things he told me, I began scrutinizing the walls very attentively. It amused me to examine these sheets, yellowed by time, all speckled over with some kind of hieroglyphs whose meaning escaped me completely but which, I felt, must signify something very wise and interesting. And I would stand by the wall for hours on end, reading and rereading what was written there. (Kovalevskaya, 1978, p. 215, added emphasis)

That this kind of encounter with the patterns on such makeshift wallpaper entails social guidance - the mentioned Uncle, who had been regularly chatting with the girl:

Uncle used to tell me fairytales and teach me how to play chess. Then, unexpectedly carried away by his own thoughts, he would initiate me into the secrets of the various economic and social projects through which he dreamed of benefitting humanity. But more than anything else, he loved to communicate the things he had succeeded in reading and learning in the course of his long life.

It was during these conversations that I first had occasion to hear about certain mathematical concepts which made a very powerful impression upon me. Uncle spoke of "squaring the circle," about the asymptote - that straight line which the curve constantly approaches without ever reaching it - and about many other things which were quite unintelligible to me and yet seemed mysterious and at the same time deeply attractive. (ibid, p. 214, added emphasis)
The girl - Sofia Kovalevskaya - became one of the most celebrated and original mathematicians of the $19^{\text {th }}$ century when there was no educational discussion of few women in the hard sciences, or the "math phobia" in schools, etc. Women were simply not in academia - being forbidden to attend university courses - yet the highly dedicated and motivated ones prevailed and excelled. No social institution was offering to "help" them to "overcome" their supposed "inferiority" - rather, the unconditionally repressive social system triggered various trajectories of resilience. Some of these proved to result in excellence in the sciences

What emerges as an important point from this example is the role of episodic synthesis (see Vygotsky, 1971) of the interpersonal (listening to the talkative uncle) and individual experiences (reading the wallpaper). The way in which development works is not that of active teaching-and-learning in the hereand-now special setting (a school lesson), but rather a bricolage of moments of haphazard social suggestions and occasional links with environment through concentrated attention. Life is not an institutionalized training ground where the more experienced "social others" teachers, parents, peers - do their utmost in the lesson framework to bring the "novices" to the ever-expanding horizons of new knowledge. Instead, knowledge is acquired in an ambivalent social maze of limitations, bogus value attributions, pretense of "help" to mask acts of appropriation, and so on. Developing ignorance - under the cover of "choice", "opportunity", and "right to know" is an important social goal orientation for any profit-oriented social institution in a globalizing consumer society. Filling our lives with ornaments through the television commercials of our day, similar to church decorations in the pre-literate eras - is a vehicle amply used in implicit social guidance of human development. 


\section{General Conclusions}

Ornaments are bases for holistic experiencing - and holistic abstraction. Hence the power of abundance - including here its null case (absence of ornament) for the human psyche. An ornamented world keeps the experiencing person "within the field" - not letting him/her escape, while at the same time not particularly demanding attention or goals-oriented actions in relation to the patterns. It is therefore not surprising that the function of ornaments has been viewed usually in terms of aesthetics, rather than those for psychological development.

Both biological and cultural worlds create human life conditions in the form of multiple potentially infinite fields that are abundant. We can consider human development as a coordination - with qualitative ruptures - of two holistic fields of external and internal infinities of pattern transformation. Within these coordinated fields, the principle of redundancy guarantees multi-faceted canalization of the developing organism in socially desirable directions.

\section{Acknowledgment}

The pleasures of Chinese food in Copenhagen - and discussions with Marianne Hedegaard, Pernille Hviid, Jytte Bang, and Charlotte Mathiassen - set the foundation for this synthesis of architecture and human development. I am grateful to Max Berkowitz for our recurrent discussions of the nature of science, and for his provision of the lead for the Kovalevskaya example. Suggestions by two unknown editorial reviewers were helpful for bringing this article to its completion.

\section{References}

Badyaev, A. V. and Landeen, E. A. (2007). Developmental evolution of sexual ornamentation: model and a test of feather growth and pigmentation. Integrative and Comparative Biology, 47, 2, 221-233.

Demmer, U. (1997). Voices in the forest: The field of gathering among the Jenu Kurumba. In P. Hockings (Ed.), Blue Mountains revisited: Cultural studies on the Nilgiri Hills (pp. 164-191). Delhi: Oxford University Press.

Diriwächter, R. and Valsiner, J. (Eds) (2008). Striving towards the whole. New Brunswick, N.J.: Transaction Publishers.

Ehrenfels, C. von (1890/1988) On Gestalt qualities. In B. Smith (Ed)., Foundation of Gestalt theory. München: Philosophia Verlag.

Foster, M. L. (1979). Synthesis and antithesis in Balinese ritual. In A. L. Becker and A. A. Yengoyan (Eds.), The imagination of reality: Essays on Southeast Asian coherence systems (pp. 175-196). Norwood, N.J.: Ablex.

Goodale, J. C. (1995). To sing with pigs is human: The concept of person in Papua New Guinea. Seattle, Wa.: University of Washington Press.

Hamlin, A. D. F. (1923). A history of ornamentRenaissance and modern. New York: The Century.

Jones, O. (1856/2001). The grammar of ornament. New York: Ivy Press.

Josephs, I. E., Valsiner, J., \& Surgan, S. E. (1999). The process of meaning construction. In J. Brandtstätdter and R. M. Lerner (Eds.), Action \& self development (pp. 257-282). Thousand Oaks, Ca.: Sage.

Kovalevskaya, S. (1978). A Russian childhood. New York: Springer.

Lawrence, J. A., \& Valsiner, J. (1993). Conceptual roots of internalization: From transmission to transformation. Human Development, 36, 150-167.

Lawrence, J. A., \& Valsiner, J. (2003). Making personal sense: An account of basic internalization and externalization processes. Theory \& Psychology, 13, 6, 723-752.

Leach, E. (2000/1983). The gatekeepers of heaven. In S. Hugh-Jones \& J. Laidlaw (Eds.), The essential Edmund Leach. Vol. 2. Culture and 
human nature (pp. 119-140). New Haven, Ct.: Yale University Press.

Morgan, D.(1998). Visual piety: a history and theory of popular religious images. Berkeley, Ca.: University of California Press.

Roche, D. (1996). The culture of clothing. Cambridge: Cambridge University Press.

Salingaros, N. A. (1996). The "life" of a carpet: an application of the Alexander rules. Paper presented at the $8^{\text {th }}$ International Conference on Oriental Carpets, Philadelphia, Pa. November.

Turner, V. (1974). Dramas, fields and metaphors. Ithaca, N.Y.: Cornell University Press.

Valsiner, J. (1997). Culture and the development of children's action. $2^{\text {nd }}$ ed. New York: Wiley.

Valsiner, J. (2005). Affektive Entwicklung im kulturellen Kontext. In J. B. Asendorpf (Ed.), Enzyklopädie der Psychologie. Vol. 3. Soziale, emotionale und Persönlichkeitsentwicklung (pp. 677-728). Göttingen: Hogrefe.

Valsiner, J. (2006). The overwhelming world: Functions of pleromatization in creating diversity in cultural and natural constructions. Keynote lecture at International School of Semiotic and Structural Studies, Imatra, Finland, June, 12.

Valsiner, J. (2007a). Culture in minds and societies. New Delhi: Sage.

Valsiner, J. (2007b). Constructing the internal infinity: dialogic structure of the internalization/ externalization process. International Journal of Dialogical Science, 2, 1, 207-221. [http:// ijds.lemoyne.edu/journal/2_1/index.html]

Valsiner, J., \& Rosa, A. (2007). Contemporary socio-cultural research: uniting culture, society, and psychology. In J. Valsiner \& A. Rosa (Eds.), The Cambridge Handbook of Sociocultural Psychology (pp. 1-20) New York: Cambridge University Press.

von Uexküll, J. J. (1982). The theory of meaning. Semiotica 42, 1, 25-82. (Original Bedeutungslehre from 1940).

Vygotsky, L. S. (1971). Psychology of art. Cambridge, Ma.: MIT Press.

Wisse, G. (1994). Manifold beginnings: singlesheet papers.. In L. Hoskins (Ed.), The papered wall (pp. 8-21). New York: Harry Abrams.

Wörringer, W. (1963). Abstraction and empathy:
A contribution to the psychology of style. New York: International Universities Press.

Zittoun, T. (2006). Transitions. Stamford, Ct,: InfoAge Press. 